\title{
On the Meaning and Measure of Narcissism
}

\section{Ryan P. Brown \\ Karolyn Budzek \\ Michael Tamborski}

The University of Oklahoma
For three decades, social-personality research on overt narcissism has relied almost exclusively on the Narcissistic Personality Inventory (NPI). However, the NPI suffers from a host of psychometric and validity concerns that make composite NPI scores (summed across its subscales) difficult to interpret. The present studies propose that narcissistic characteristics tend to fall under two general clusters: grandiosity and entitlement. The studies show that measures of grandiosity and entitlement interact to predict scores on the NPI, controlling for gender, self-esteem, and basic personality (Study 1), but also that grandiosity and entitlement function independently with respect to mental health (Study 2) and ethical misconduct (Study 3). Together, these results challenge the view of overt narcissism as a unidimensional construct and underscore the importance of distinguishing between grandiose and entitled aspects of the narcissistic self-concept.

Keywords: narcissism; grandiosity; entitlement; mental health; misconduct

$\mathrm{N}$ arcissism is one of the oldest constructs in the history of psychology, but for most of this history it has developed under the guidance of psychodynamic theorists. Over the past several decades, however, narcissism has received increasing attention by social and personality psychologists, perhaps as an outgrowth of their corresponding interest in self-esteem and selfregulation. As social-personality research on narcissism progresses with increasing methodological and statistical sophistication, it might be time to rethink the way we approach narcissism, both theoretically and empirically. The present studies present an alternative to the common conceptualization and measurement of narcissism and suggest that an appreciation of the dimensionality of the narcissistic self is crucial to understanding the construct.
Several divergent perspectives on narcissism have guided theory and research in recent years (e.g., Kernberg, 1975; Morf \& Rhodewalt, 2001; Westen, 1990). But across the spectrum of clinical, developmental, and socialpersonality theories of narcissism, grandiosity seems to be the most central characteristic (Buss, 1991). The Diagnostic and Statistical Manual of Mental Disorders (DSM-IV-TR; American Psychiatric Association, 2000) lists a grandiose sense of self-importance as the primary element of narcissism, along with an excessive need for the admiration of others, arrogance, a sense of "uniqueness" and entitlement, a lack of empathy, envy, and a tendency to exploit others.

Somewhat consistent with these defining characteristics, studies suggest that people with high scores on the Narcissistic Personality Inventory (NPI; Raskin \& Hall, 1979) tend to react in self-serving and aggressive ways to self-esteem threats (Bushman \& Baumeister, 1998) and exhibit excessive emotional volatility following positive and negative feedback (Rhodewalt \& Morf, 1998). Furthermore, studies show that high scores on the NPI are associated with high self-esteem and selffocused attention (Emmons, 1987; Morf \& Rhodewalt, 1993; Raskin, Novacek, \& Hogan, 1991), need for power (Carroll, 1987), and interpersonal dominance (Brown \& Zeigler-Hill, 2004). Likewise, high scores on the NPI are associated with low levels of agreeableness, high levels of extraversion (Rhodewalt \& Morf, 1995), and a low need for intimacy (Carroll, 1987).

Authors' Note: Correspondence concerning this article should be sent to Ryan P. Brown, 455 W. Lindsey, DHT 705, Department of Psychology, The University of Oklahoma, Norman, OK 73019; e-mail: rpbrown@ou.edu.

PSPB, Vol. 35 No. 7, July 2009 951-964

DOI: $10.1177 / 0146167209335461$

(C) 2009 by the Society for Personality and Social Psychology, Inc. 


\section{Critique of the NPI}

Most studies on narcissism within social-personality psychology operationally define high levels of narcissism as high scores on the NPI. However, the meaning of scores on this scale remains obscured by a haze of psychometric and validity questions. For example, the factor structure of the NPI has been in question since its inception. The scale was originally published in a 54-item, forced-choice format without subscales (Raskin \& Hall, 1979). In two validation studies, Emmons (1984, 1987) suggested a 37-item, forced-choice format with four subscales: leadership/authority (L/A), self-admiration/ self-absorption (S/S), superiority/arrogance (S/A), and exploitiveness/entitlement (E/E). Raskin and Terry (1988) later argued for a 40-item, forced-choice measure with seven subscales: authority, exhibitionism, superiority, entitlement, exploitativeness, self-sufficiency, and vanity. A more recent analysis of the NPI identified only three factors (Kubarych, Deary, \& Austin, 2004). Nevertheless, most researchers who use the NPI to assess narcissism simply sum across the subscales to create a total score. This scoring approach might be partly due to the generally poor reliability of the subscales, with alphas in large samples ranging from .42 to .75 (e.g., Trzesniewski, Donnellan, \& Robins, 2008).

Both the 37- and 40-item versions of the NPI are widely used, either with or without their respective subscales. However, when researchers report subscale correlates, they most frequently focus on the $\mathrm{E} / \mathrm{E}$ factor. This factor, when reported, often diverges empirically from the other subscales of the NPI. For example, Rhodewalt and Morf (1995) reported that although the total NPI was strongly correlated with self-esteem and self-certainty, E/E was unrelated to both. In the same study, the total NPI was negatively related to the magnitude of actual-ideal self-discrepancies, but E/E was positively related to these self-discrepancies. E/E was also negatively related to perceived social support, unlike the total NPI. Likewise, Hickman and colleagues found that the total NPI predicted optimism, low hopelessness, and high expected positive affect, but $\mathrm{E} / \mathrm{E}$ was unrelated to all of these variables (Hickman, Watson, \& Morris, 1996). Differences between the E/E subscale and the total NPI appear with respect to other variables as well, including several basic personality dimensions (Hendin \& Cheek, 1997) and interpersonal forgiveness (Exline, Baumeister, Bushman, Campbell, \& Finkel, 2004).

Besides these psychometric problems, the content of the NPI has also come under fire. Echoing Emmons (1987), Rosenthal and Hooley (2008) have argued that although some of the items on the NPI seem to capture narcissistic features (e.g., arrogance and exploitiveness), other items reflect qualities that are not necessarily narcissistic (e.g., leadership). In one study, Rosenthal and Hooley had clinicians rate each item of the NPI for how well it reflected narcissistic tendencies. On the basis of these ratings, Rosenthal and Hooley separated the items into three sets representing a high, moderate, or low degree of narcissism, and correlated scores on these three item sets with scores on an index of narcissistic personality disorder (NPD) derived from the DSM-IV-TR, and a measure of healthy self-esteem. Results indicated that the highly narcissistic set of NPI items was strongly correlated with the NPD measure but not with healthy self-esteem, whereas the opposite was true for the least narcissistic set of NPI items. Thus, besides being psychometrically weak, many of the items on the NPI do not appear to reflect narcissism at all, making summary scores across the NPI subscales conceptually ambiguous.

In addition to the occasional reference to differences among subscale correlates, some researchers have used the factors of the NPI to distinguish between so-called adaptive and maladaptive types of narcissism. Watson and colleagues, for instance, have capitalized on the difference between scores on the E/E subscale and total NPI scores by using the $\mathrm{E} / \mathrm{E}$ scale as a measure of maladaptive narcissism and a composite of the remaining subscales as a measure of adaptive narcissism (e.g., Soyer, Rovenpor, Kopelman, Mullins, \& Watson, 2001; Watson \& Biderman, 1993; Watson \& Morris, 1990; see also Dickinson \& Pincus, 2003). This line of research suggests that the NPI might simply be capturing two distinct but equally legitimate forms of narcissism, although this conclusion depends on whether the adaptive form is really anything more than normal self-esteem or self-confidence (see Sedikides, Rudich, Gregg, Kumashiro, \& Rusbult, 2004). Related arguments have been made about overt and covert types of narcissism (Wink, 1991). Although the validity of the covert narcissism construct is questionable, most socialpersonality research has focused on overt narcissism, the typical measure of which remains the NPI.

\section{Grandiosity and Entitlement as a Dimensional Framework}

If the NPI appears insufficient as a measure of overt levels of narcissism, and most alternative measures, which are typically based on the Minnesota Multiphasic Personality Inventory (e.g., Hendin \& Cheek, 1997; Wink, 1991), lack even the modest degree of face validity exhibited by the NPI, how else might we measure this fascinating construct? One approach is to start with the defining characteristics of narcissism listed in the DSM-IV-TR, just as Raskin and Hall (1979) did with the Diagnostic Statistical Manual of Mental Disorders (3rd ed.; DSM-III), and devise items that reflect these defining characteristics. Our own examination of these 
characteristics led us to conclude that they form two clusters: one that is primarily intrapersonal and concerned with a grandiose sense of self-importance, and one that is more interpersonal and concerned with an entitled, socially objectifying sense of the self in relation to others. These intrapersonal and interpersonal clusters are interesting to consider in light of their overlap with the agency and communion distinction within the interpersonal circumplex model of personality (Leary, 1957; Wiggins, 1979). Indeed, interpersonal circumplex researchers have argued that narcissism reflects a combination of a high degree of agency (e.g., a sense of power, status, and independence) and a low degree of communion (e.g., a lack of interpersonal warmth and a rejection of affiliative qualities; see also Ruiz, Smith, \& Rhodewalt, 2001; Wiggins \& Pincus, 1994). This high-agency and low-communion model is consistent with our suggestion of an intrapersonal-interpersonal distinction among the defining features of narcissism in the DSM-IV-R, although the overlap between these models is imperfect, particularly given that high agency is considered to be an interpersonal dimension within the circumplex framework, whereas grandiosity is more of an intrapersonal dimension in our framework.

The interpersonal circumplex provides a potentially useful framework for relating narcissistic tendencies to basic dimensions of personality. Nonetheless, we believe that scales designed to measure agency and communion are unlikely to be especially effective at capturing the pathological extremity of narcissistic characteristics. What, then, can be used to assess the interpersonal and intrapersonal aspects of narcissism within the dimensional framework that we are proposing? We suggest that two recently developed scales might capture the essence of the intrapersonal and interpersonal clusters of narcissistic characteristics described in the DSM. Specifically, we propose that Rosenthal, Hooley, and Steshenko's (2007) Narcissistic Grandiosity Scale captures the overinflated sense of arrogant self-importance that is one of the central features of narcissism. Indeed, the items on the Narcissistic Grandiosity Scale (which we describe in more detail in Study 1) provide one of the best descriptions of narcissistic self-inflation that we have seen in the narcissism literature.

Alongside this intrapersonal dimension, we believe that Campbell, Bonacci, Shelton, Exline, and Bushman's (2004) Psychological Entitlement Scale captures the sense of interpersonal deservedness and objectification of others that seem to lie at the heart of the interpersonal dimension of narcissism. Although other perspectives on this interpersonal dimension might emphasize different relational aspects of narcissism, such as a lack of empathy or aggressiveness, we believe that these qualities may be secondary emotional and behavioral manifestations of the objectifying belief of the narcissist that, as Sedikides, Campbell, Reeder, Elliot, and Gregg (2002) described it, "others exist for me." Studies by Campbell et al. on the interpersonal consequences of entitlement beliefs support this assertion, alongside other studies showing that the E/E subscale of the NPI often carries the bulk of the variance in antisocial feelings and behaviors associated with the full NPI (e.g., Exline et al., 2004; Rhodewalt \& Morf, 1995). Thus, although other approaches to this interpersonal dimension might be fruitful, we suspect that the belief that one is entitled to more goods, more benefits, and more rights than are other people adequately captures the heart of this dimension.

In the present studies, we examine scores on the NPI (Study 1), indices of mental health (Study 2), and aspects of misconduct (Study 3 ) as a function of narcissistic grandiosity and entitlement. In all three studies, we examine both the main effects and the interaction of grandiosity and entitlement. If narcissism entails both a high degree of grandiosity and a high degree of entitlement, one of two outcomes should occur. First, grandiosity and entitlement might evidence independent, additive associations with the outcome variables of interest, such that the highest scores on our dependent measures would be obtained by people who are high in both grandiosity and entitlement. Second, grandiosity and entitlement might interact monotonically, which would indicate a synergistic version of the independentbut-additive pattern. With either of these two patterns, narcissistic individuals would be those high in both the intrapersonal and the interpersonal characteristics described in the DSM-IV-TR. If either of these patterns does not appear, we might need to rethink what it means to be a narcissist. We also include the NPI itself in these studies to replicate previous findings with this measure while demonstrating the value of taking a more nuanced, dimensional approach to the narcissism construct.

\section{STUDY 1: GRANDIOSITY, ENTITLEMENT, AND THE NPI}

Given the tendency of social and personality researchers to rely so heavily on the NPI, Study 1 investigated scores on the NPI as a function of grandiosity, entitlement, and their interaction, along with gender and healthy selfesteem. Furthermore, we investigated the associations between each of these scales and the dimensions of the Big Five, with particular emphasis on extraversion and agreeableness, in keeping with previous arguments that narcissism can be described as a combination of high extraversion and low agreeableness (e.g., Paulhus, 2001). 


\section{Method}

\section{Participants and Procedure}

Seven hundred fifty-four participants completed the narcissism measures as part of a larger, online survey in partial fulfillment of a research exposure requirement in introductory psychology at The University of Oklahoma. However, 14 participants did not provide complete responses to the other personality or selfesteem scales that we examined in this study, so their data were excluded from all analyses, leaving a total of 740 participants (460 females, 280 males) in the final sample. Of these, approximately $76 \%$ identified themselves as Caucasian, $6 \%$ as Black, $5 \%$ as Native American, $7 \%$ as Asian or Pacific Islander, 3\% as Hispanic or Latino/a, and $2 \%$ as Other.

\section{Measures}

All measures described here were administered in individually randomized orders, along with a battery of additional attitude and personality scales unrelated to the present investigation.

Narcissism. Three measures of narcissism were administered. First, we administered the 37-item, forced-choice version of the NPI (Emmons, 1987). On this scale, participants chose which items within 37 pairs described them best. Example pairs include "When people compliment me I sometimes get embarrassed" versus "I know that I am good because everybody keeps telling me so," and "I like having authority over other people" versus "I don't mind following orders." Cronbach's alpha for the total NPI was good $(\alpha=.83)$. Each of the four NPI subscales described by Emmons $(1984,1987)$ was also calculated, and subscale reliability estimates were, predictably, less impressive than for the total scale $(\alpha s=.57, .59, .65$, and .78 for E/E, S/A, S/S, and L/A, respectively).

In addition to the NPI, we also administered Rosenthal et al.'s (2007) Narcissistic Grandiosity Scale and Campbell et al.'s (2004) Psychological Entitlement Scale. The grandiosity scale $(\alpha=.95)$ contains 16 trait adjectives or phrases, and respondents are directed to rate the extent to which each describes them "in general" using 7-point Likert scales ranging from 1 (not at all) to 7 (extremely). Example items are "perfect," "glorious," and "omnipotent," which clearly reflect a grandiose sense of selfimportance. The entitlement scale $(\alpha=.88)$ contains nine statements with which respondents rate their agreement on 7-point Likert scales ranging from 1 (strongly disagree) to 7 (strongly agree). Example statements are "I honestly feel I'm just more deserving than others" and "I feel entitled to more of everything." As these examples show, the face validity of the grandiosity and entitlement scales is high, and consistent with their strong internal reliability estimates, prior evidence reveals them to be valid, unidimensional indices of their respective constructs (Campbell et al., 2004; Rosenthal et al., 2007).

Big Five. For our secondary analyses, we administered John, Donahue, and Kentle's (1991) Big Five Inventory (BFI), a widely used instrument that assesses the five basic personality domains of extraversion, agreeableness, neuroticism, conscientiousness, and openness to experience. In the current sample, reliability estimates for each dimension were good, ranging from $\alpha=.78$ (conscientiousness) to $\alpha=.87$ (extraversion). Respondents rated the extent to which each of these statements was true for them using a 5-point Likert scale ranging from 1 (strongly disagree) to 5 (strongly agree).

Self-esteem. Scores on the NPI are typically correlated with measures of self-esteem, depending on the extent to which those measures are oriented toward social dominance (Brown \& Zeigler-Hill, 2004). To assess a relatively non-narcissistic facet of healthy self-esteem as a control variable, we administered the 10-item Rosenberg Self-Esteem Scale (RSE; Rosenberg, 1965). Example items from the RSE $(\alpha=.89)$ are "I feel that I'm a person of worth, at least on an equal basis with others" and "On the whole, I am satisfied with myself." Respondents rated the extent to which each of these statements was true for them using a 4-point Likert scale ranging from 1 (strongly disagree) to 4 (strongly agree).

\section{Results}

\section{Zero-Order Associations}

Table 1 presents descriptive statistics for and intercorrelations among the measures of narcissism, personality, and self-esteem. Grandiosity and entitlement were significantly correlated with one another $(r=.44)$, and both were also correlated with the NPI as well as each of its subscales. However, grandiosity $(r=.54)$ was more strongly related to the total NPI than was entitlement $(r=.36), t(737)=5.47, p<.001$, just as with the RSE, $t(737)=6.45, p<.001$. The correlation between the RSE and the NPI $(r=.16)$ fell between the correlations of the RSE with grandiosity and entitlement. Grandiosity was somewhat more strongly correlated with each of the subscales of the NPI than was entitlement, with the exception of the NPI's E/E subscale, which was more strongly correlated with the entitlement scale than with grandiosity, $t(737)=3.04, p<.01$. Grandiosity and entitlement showed generally modest associations with the facets of the BFI, with grandiosity $(r=.27)$ correlating more strongly with extraversion than entitlement did $(r=.03)$, 


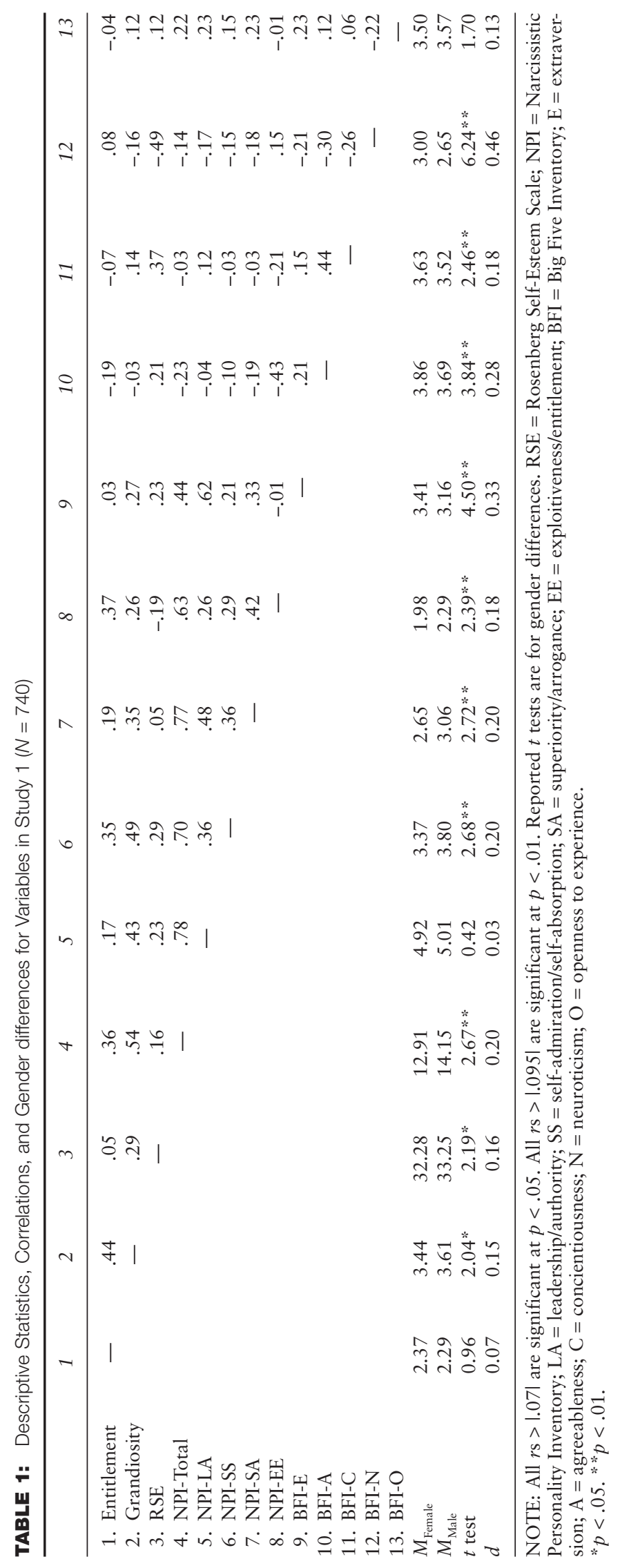


$t(737)=6.42, p<.001$, but entitlement $(r=-.19)$ correlating more strongly with agreeableness than grandiosity $\operatorname{did}(r=-.03), t(737)=4.18, p<.001$. The NPI correlated even more strongly with extraversion $(r=.44)$ than grandiosity did $(r=.27), t(737)=5.33, p<.001$, and slightly more strongly with agreeableness $(r=-.23)$ than entitlement did $(r=-.19), t<1, n s$. Thus, scores on the NPI were somewhat more reducible to facets of normal personality than were scores on the grandiosity and entitlement scales. Small but significant gender differences appeared on most of the measures (and their respective subscales), with the exception of the leadership/authority subscale of the NPI and the entitlement scale.

\section{Plotting the NPI With Grandiosity and Entitlement}

We next examined grandiosity and entitlement and their interaction (after mean-centering both variables; Aiken \& West, 1991) as predictors of NPI scores in a multiple regression equation. In this analysis, we controlled for gender (coded as $0=$ female, $1=$ male) and the RSE. Grandiosity $(\beta=.47, p<.001, d=0.99)$ and entitlement $(\beta=.14, p<.001, d=0.31)$ each accounted for unique variance in NPI scores. Furthermore, grandiosity and entitlement also interacted significantly $(\beta=.12$, $p<.001, d=0.28$ ) such that the highest scores on the NPI were obtained by respondents who scored high on both grandiosity and entitlement, as shown in Figure 1. Gender was also a significant factor in this analysis $(\beta=.07$, $p<.05, d=0.17$ ), but the zero-order association between the RSE and the NPI was no longer significant with grandiosity and entitlement in the model $(\beta=.02$, $n s)$. This model accounted for approximately $33 \%$ of the variance in NPI scores.

\section{Disagreeable Extraverts?}

Paulhus (2001) and others have proposed that narcissism might reduce simply to high extraversion and low agreeableness. We examined this notion by adding the mean-centered BFI extraversion and agreeableness subscales-as well as their interaction-to the prior regression equation predicting scores on the NPI. Results of this analysis, which are shown in Table 2, revealed that gender, agreeableness, and extraversion (but not the Agreeableness $\times$ Extraversion interaction) were all statistically significant predictors of NPI scores, but despite these covariates, grandiosity, entitlement, and their interaction still accounted for significant variance in NPI scores, and the pattern of their associations with the NPI remained essentially unchanged from what is shown in Figure 1. This full model accounted for approximately $50 \%$ of the variance in NPI scores, a substantial increase from the model that did not include agreeableness and extraversion.

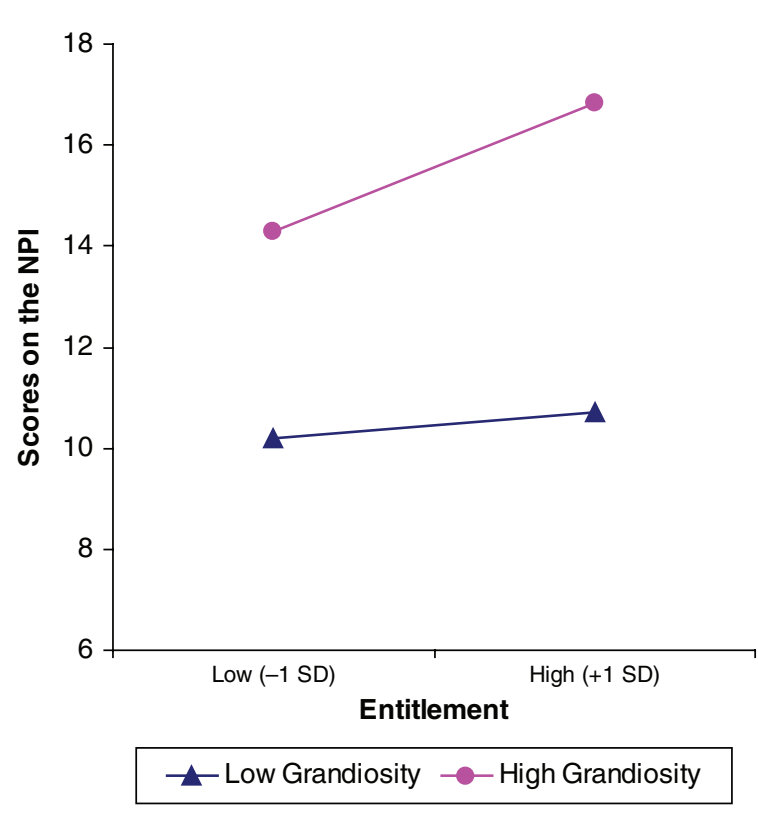

Figure 1 NPI scores as a function of narcissistic grandiosity and entitlement.

NOTE: NPI = Narcissistic Personality Inventory

TABLE 2 Regression Results Predicting NPI Scores in Study 1

\begin{tabular}{|c|c|c|c|c|}
\hline Variable & $B$ & $S E B$ & $\beta$ & $d$ \\
\hline Gender & 1.31 & 0.34 & $.10 * *$ & 0.28 \\
\hline RSE & 0.01 & 0.03 & .01 & 0.03 \\
\hline Agreeableness (A) & -2.77 & 0.30 & $-.26 * *$ & 0.68 \\
\hline Extraversion $(\mathrm{Ex})$ & 3.29 & 0.23 & $.41^{* *}$ & 1.06 \\
\hline $\mathrm{A} \times \mathrm{Ex}$ & 0.08 & 0.33 & .01 & 0.02 \\
\hline Grandiosity (G) & 1.88 & 0.17 & $.34 * *$ & 0.80 \\
\hline Entitlement (E) & 0.82 & 0.17 & $.15 * \%$ & 0.36 \\
\hline $\mathrm{G} \times \mathrm{E}$ & 0.41 & 0.12 & $.09 *$ & 0.26 \\
\hline
\end{tabular}

Note. $R^{2}=.50$. Gender coded as $0=$ female, $1=$ male. RSE $=$ Rosenberg Self-Esteem scale.

$* p<.01 . * p<.001$.

\section{Discussion}

The focus of Study 1 was on the associations between scores on the NPI and two indices of narcissistic characteristics-specifically, a grandiose self-image and a sense of special entitlement. Grandiosity and entitlement were positively related to each other, but this relation was only moderate in magnitude. Thus, grandiosity and entitlement appear to capture distinguishable constructs despite both appearing to be overtly narcissistic. Furthermore, grandiosity and entitlement accounted for unique variance in scores on the NPI, and they significantly interacted, such that the highest NPI scores were predicted by high scores on both grandiosity and entitlement; 
however, absent high grandiosity, entitlement was not strongly related to the NPI. These associations occurred despite our controlling for basic facets of personality, gender, and healthy self-esteem.

Some evidence in Study 1 supported the notion that narcissists are "disagreeable extraverts" (Paulhus, 2001). For example, scores on the NPI were positively related to extraversion and negatively related to agreeableness. However, extraversion and agreeableness did not interact to predict scores on the NPI, and the interaction between grandiosity and entitlement predicting the NPI held even when agreeableness and extraversion (and their interaction) were added to the model. Thus, these analyses suggest that although people with high scores on the NPI might tend to be disagreeable extraverts, this is not all they are. That extraversion and agreeableness remained significantly related to the NPI in the model that included grandiosity and entitlement is also interesting. This result shows that the NPI reflects more than just the grandiose sense of self-importance and special sense of entitlement that we have argued form the core of the intrapersonal and interpersonal dimensions of the narcissism construct. Whether this "more" indicates a strength or a weakness of the NPI depends on the validity of our model and of the grandiosity and entitlement scales as measures of the core features of narcissism.

We should also note that the data from Study 1 support our concerns about the meaning of composite scores on the NPI. The correlations in Table 1 reveal that the subscales of the NPI did not operate consistently with respect to measures of grandiosity, entitlement, self-esteem, or basic personality. For example, although L/A and S/S both correlated positively with self-esteem, S/A did not, and E/E correlated negatively with self-esteem. This pattern seems problematic for interpreting the meaning of scores on the NPI and its subscales. What, after all, does it mean to score high on a measure of "superiority and arrogance" without scoring high in self-esteem? Other differences between the NPI subscales can also be seen in their associations with the facets of the BFI. For instance, extraversion varied widely in its association with the NPI subscales, ranging from a high of $r=.62$ with L/A to a low of $r=-.01$ with $\mathrm{E} / \mathrm{E}$. Likewise, subscale correlations with agreeableness ranged from a high of $r=-.43$ with $\mathrm{E} / \mathrm{E}$ to a low of $r=-.04$ with L/A. Other distinct patterns of association between the facets of the BFI and the subscales of the NPI also occurred, and these distinctions call into question the validity of computing a "total narcissism score" by simply summing across the NPI subscales. Indeed, a parallel might be drawn between summing across the subscales of the NPI to create a "total narcissism score" and summing across the dimensions of the Big Five to create a "total personality score."
How, then, should researchers measure narcissism? Summing across the NPI's subscales seems inappropriate, given the large differences in associations between these subscales. However, simply treating these subscales independently is also problematic, given the rather modest reliability of the subscales (in this and most other studies that report them), and a careful examination of the actual items of the NPI calls into question what some of them are really measuring. Although the NPI has performed well enough to be used repeatedly in social-personality research over the last several decades, we are left to wonder why it does so. In other words, what aspects of narcissism captured by the NPI are responsible for the significant associations between total NPI scores and the host of antecedents and consequences that prior research has revealed? In the next two studies, we address this question by examining grandiosity and entitlement in the context of mental health (Study 2) and misconduct (Study 3), contrasting the results obtained with these alternative indices of narcissistic characteristics and results obtained using the NPI.

\section{STUDY 2: NARCISSISM AND MENTAL HEALTH}

Study 2 examined the associations between narcissistic grandiosity, narcissistic entitlement, and four indices of mental health. If narcissistic grandiosity reflects a defensive, compensatory self-inflation, its relation to mental health might be negative insofar as defensive compensation strategies exist to mask underlying insecurities and pathologies. However, the same self-deceptive cognitive style that would support a grandiose self-concept could also facilitate the sorts of positive illusions that seem to enhance subjective well-being (Taylor $\&$ Brown, 1988). This perspective on the nature of narcissistic grandiosity would lead to the hypothesis that grandiosity should be positively associated with mental health. This argument is also consistent with research by Sedikides et al. (2004), who found that scores on the NPI were positively associated with self-report measures of mental health and that this association was mediated fully by self-esteem. Because grandiosity covaries with normal self-esteem (Study 1), just as scores on the NPI do (Emmons, 1987), self-esteem might also account for the association between grandiosity and well-being, a possibility that we examined in the present study.

In contrast, we did not expect narcissistic entitlement to be predictive of well-being. Although the additive and interactive models of narcissism would predict that individuals high in both grandiosity and entitlement ought to exhibit the highest levels of any variable attributable to the construct of narcissism, we see little reason to 
expect that people high in entitlement would be particularly happy, optimistic, or satisfied with their lives. This skepticism is consistent with prior research on mental health and the NPI, which has not found the E/E factor to be positively associated with well-being (e.g., Hickman et al., 1996), as well as with the failure of entitlement scores in Study 1 to be strongly related to self-esteem. Thus, even though grandiosity and entitlement interacted to predict NPI scores in Study 1, and NPI scores have been positively associated with mental health in previous studies (e.g., Sedikides et al., 2004), we did not expect either an additive or an interactive model to hold in this study because of the hypothesis that high levels of entitlement would not be positively associated with well-being.

\section{Method}

\section{Participants and Procedure}

Three hundred six undergraduates (213 female, 93 male; mean age $=19.3$ years) at The University of Oklahoma participated in an online survey in exchange for credit toward a research exposure requirement in their introductory psychology courses. Approximately $78 \%$ of the sample self-identified as Caucasian, $6.6 \%$ as Asian or Pacific Islander, $5.2 \%$ as Black, $4.6 \%$ as Hispanic or Latino/a 3.6\% as Native American, and $2.6 \%$ as Other (or did not indicate an ethnicity). Participants completed the questionnaires described here, along with several other measures unrelated to the present study, in individually randomized orders.

\section{Measures}

As in Study 1, participants completed the NPI along with measures of grandiosity and entitlement, all of which demonstrated strong internal reliability ( $\alpha \mathrm{s}=.85$, .95 , and .86 , respectively). The failure of 18 participants to complete the entire NPI resulted in only 288 respondents for the NPI analyses. Restricting the sample to these 288 participants did not alter any of our results in a meaningful way, so we retained all available participants for the grandiosity and entitlement analyses.

To assess mental health, we administered four measures. Participants completed the Centers for Epidemiological Studies Depression Scale (CES-D; Radloff, 1977), a widely used measure of depression. On the CES-D, participants rated the frequency with which they had experienced symptoms characteristic of depression within the past week, on a 4-point scale ranging from 0 (rarely or none of the time) to 3 (most or all of the time). Example items from this 20 -item scale $(\alpha=.91)$ include "I felt depressed" and "I felt that I could not shake off the blues even with help from my family or friends." A second dimension of well-being was assessed with Diener, Emmons, Larsen, and Griffin's (1985) Satisfaction With Life (SWL) scale. Examples of this 5 -item scale $(\alpha=.86)$ include "In most ways my current life is close to my ideal" and "I am satisfied with my life." Participants rated their level of agreement with each item on the SWL on 7-point Likert scales ranging from 1 (strongly disagree) to 7 (strongly agree). Finally, participants completed the Revised Life Orientation Test (LOT-R; Scheier, Carver, \& Bridges, 1994), which is divided into 3 -item subscales for optimism $(\alpha=.70)$ and pessimism $(\alpha=.76)$. Example items include "In uncertain times, I usually expect the best" and "I rarely count on good things happening to me." Participants rated their level of agreement with the items on 5-point scales ranging from 1 (disagree strongly) to 5 (agree strongly). Finally, we administered the 10-item RSE to capture self-esteem $(\alpha=.89)$ as a possible mediator of the associations between our measures of narcissism and mental health.

\section{Results}

Correlations among the measures of grandiosity and entitlement, the NPI, mental health, and self-esteem are presented in Table 3. As this table shows, grandiosity was significantly associated with all four indices of mental health. Similar, albeit weaker, associations were obtained with the NPI. In contrast, scores on the entitlement scale were only weakly associated with optimism $(r=.13, p<.01)$ and were not significantly associated with any other mental health measure, despite being correlated with both grandiosity $(r=.49, p<.001)$ and the NPI $(r=.43, p<.001)$. The RSE was moderately associated with grandiosity, entitlement, and the NPI, and strongly associated with all four measures of mental health, although its association with entitlement was small $(r=.15, p<.01)$.

Because conducting separate mediation models for each mental health measure increases Type I errors, we created a composite mental health score by performing a principal components analysis on our four mental health measures, which resulted in a single factor that accounted for $62 \%$ of the total variance (eigenvalue $=2.48$ ). We retained an overall mental health factor score from this factor analysis for use in our primary analyses.

Our first set of analyses attempted to replicate the results of Sedikides et al. (2004) with our mental health composite, which included two of the measures used by Sedikides et al. (depression and life satisfaction) as well as two additional measures (optimism and pessimism). We first examined the association between self-reported mental health and the NPI. Controlling for gender $(\beta=-.04$, $n s, d=0.09$ ), we found that the NPI was significantly 
TABLE 3: Zero-Order Correlations Among Variables in Study 2 ( $N=288-306)$

\begin{tabular}{|c|c|c|c|c|c|c|c|c|}
\hline & 1 & 2 & 3 & 4 & 5 & 6 & 7 & 8 \\
\hline 1. Grandiosity & - & .49 & .58 & -.28 & .26 & .26 & -.20 & .39 \\
\hline 2. Entitlement & & - & .43 & -.05 & .02 & .13 & .08 & .15 \\
\hline 3. NPI & & & - & -.19 & .14 & .20 & -.15 & .29 \\
\hline 4. Depression & & & & - & -.57 & -.45 & .47 & -.62 \\
\hline 5. Satisfaction & & & & & - & .50 & -.48 & .65 \\
\hline 6. Optimism & & & & & & - & -.51 & .56 \\
\hline 7. Pessimism & & & & & & & - & -.49 \\
\hline 8. Self-esteem & & & & & & & & - \\
\hline
\end{tabular}

NOTE: All correlations $>$ I.12I are significant at $p<.05$ NPI $=$ Narcissistic Personality Inventory.

associated with mental health $(\beta=.22, p<.001, d=$ $0.45)$. Likewise, the NPI was significantly associated with the RSE $(\beta=.29, p<.001, d=0.60)$. Next, we assessed the association between scores on the RSE and mental health, again controlling for gender. As expected, the RSE was strongly associated with mental health $(\beta=.74$, $p<.001, d=2.18)$, although gender was not $(\beta=.01$, $n s, d=0.01)$. Thus, self-esteem was associated with both the NPI and mental health, making it a possible mediator of the NPI-mental health association. To test this possibility, we included the RSE in the model with the NPI and gender and found that although the RSE remained a significant predictor of mental health $(\beta=.73$, $p<.001, d=2.02)$, the NPI was no longer significant $(\beta=.01, p<.001, d=0.02)$. A Sobel test (Sobel, 1982) revealed that the association between the NPI and mental health was significantly reduced with the RSE in the model, $z=4.89, p<.001$. Thus, the RSE fully mediated the association between the NPI and our mental health composite, consistent with the results reported by Sedikides et al. (2004).

We next investigated the associations between grandiosity, entitlement, and their interaction with respect to scores on the mental health composite, controlling for gender, after first centering the continuous predictors on their means (Aiken \& West, 1991). This analysis revealed that grandiosity was positively associated with selfreported mental health $(\beta=.43, p<.001, d=0.80)$. In contrast, entitlement was negatively associated with mental health $(\beta=-.19, p<.01, d=0.34)$. This negative association stands in contrast to the absence of a zeroorder association between entitlement and the mental health composite $(r=.04, n s)$, indicating a suppression effect by grandiosity. Neither the Grandiosity $\times$ Entitlement interaction $(\beta=.07, n s, d=0.14)$ nor gender $(\beta=-.08$, $n s, d=0.17$ ) was a significant predictor in this model.

We next analyzed scores on the RSE as a function of grandiosity and entitlement. In this model, only grandiosity was significantly associated with self-esteem $(\beta=.43, p<.001, d=0.81)$. In a final step, we regressed our mental health composite on all predictor variables simultaneously and found that the RSE remained a significant predictor $(\beta=.71, p<.001, d=1.94)$, as did both grandiosity $(\beta=.13, p=.01, d=0.30)$ and entitlement $(\beta=-.14, p<.01, d=0.35)$. A Sobel test revealed that the association between grandiosity and mental health was significantly reduced with the RSE in the model, $z=6.53, p<.001$, even though grandiosity remained a significant predictor. Thus, self-esteem partially mediated the positive association between grandiosity and mental health but did not mediate the negative association between entitlement and mental health.

As a final, supplementary analysis, we attempted to replicate the interaction between grandiosity and entitlement predicting total NPI scores. A regression analysis $\left(R^{2}=.38\right)$ that included gender as a control variable $(\beta=.10, p<.05, d=0.25)$ revealed that both grandiosity $(\beta=.47, p<.001, d=1.01)$ and entitlement $(\beta=.20$, $p<.001, d=0.42$ ) independently predicted total NPI scores, but their interaction was not significant $(\beta=.08$, $p>.10, d=0.19)$. Despite this failure to replicate the small but significant Grandiosity $\times$ Entitlement interaction found in Study 1, the magnitude of the association was similar across studies.

\section{Discussion}

As Study 2 demonstrates, the linkages between narcissism and mental health appear to be a bit more complex than has been suggested by some studies relying on NPI scores to operationalize narcissism. When narcissistic grandiosity and entitlement are measured separately, these dimensions appear to relate differently to mental health. When analyzed simultaneously, grandiosity was positively associated with mental health, whereas entitlement was negatively associated with mental health. Furthermore, self-esteem partially mediated the association between grandiosity and mental health but did not do so for entitlement. In contrast, and in keeping with recent research by Sedikides et al. (2004), self-esteem fully mediated the association between 
the NPI and mental health. Thus, the patterns obtained with the narcissistic dimensions of grandiosity and entitlement were not the same as the pattern obtained with the NPI, even though the former accounted for substantial variance in the latter.

The present results also cast doubt on the broad assertion that even "normal narcissists" are mentally healthy, a conclusion that depends entirely on the operationalization of narcissism via the NPI, which may be too strongly confounded with simple self-esteem to be of much use with regard to assessing the association between narcissism and well-being. Indeed, the mediational role of selfesteem between scores on the NPI and various indices of mental health led Sedikides et al. (2004) to "wonder whether the NPI captures a great deal of variance over and above that associated with unusually high selfesteem" (p. 413). We share this concern and believe that alternative operationalizations of narcissism might shed more light on how and why narcissistic tendencies might or might not be associated with mental health. In fact, whereas narcissistic entitlement was negatively associated with mental health in Study 2, narcissistic grandiosity remained positively related to mental health even after controlling for self-esteem, suggesting that at least this facet of narcissism is not fully reducible to simple self-esteem in its association with well-being. It may well be that the mechanisms that support the belief that one is omnipotent, glorious, and perfect also foster positive illusions that blunt the impact of life's trials and tribulations, contributing to subjective well-being beyond the well-documented benefits of high self-esteem (Taylor \& Brown, 1988). Of course, because the present data are correlational, we must be cautious in inferring a causal link between these constructs.

\section{STUDY 3: NARCISSISM AND MISCONDUCT}

So far, we have examined the distinctions between grandiosity and entitlement with respect to self-report variables. In Study 3, we investigated a behavioral variable-specifically, two forms of cheating. Von Hippel, Lakin, and Shakarchi (2005) distinguished between deliberative cheating, in which people explicitly intend to engage in misconduct, and rationalized cheating, in which people do not explicitly intend to engage in misconduct but are able to "spin" their behavior in such a way that they can construe it as something other than cheating. In Study 3, we used the paradigm devised by von Hippel et al. to examine the ability of grandiosity and entitlement to predict these forms of misconduct.

Based on data from Studies 1 and 2, we hypothesized that narcissistic entitlement would be more strongly related to deliberative cheating than would grandiosity.
Not only was entitlement more strongly related to low levels of agreeableness (a trait that reflects an explicitly prosocial orientation) than was grandiosity, but Campbell et al.'s (2004) research revealed that higher entitlement scores were predictive of a greater propensity to engage in antisocial behavior, including stealing candy from children. Thus, entitlement appears to reflect an overt rejection of social norms, which suggests that people high in entitlement are likely to ignore moral or ethical prohibitions against deliberative cheating. In contrast, we hypothesized that grandiosity would be more strongly related to rationalized cheating than would entitlement. Grandiosity appears to reflect a self-serving mind-set that goes beyond mere high self-esteem, potentially promoting a sense of subjective well-being (consistent with the correlational data reported in Study 2) that might facilitate the kind of subtle "spin" that underlies rationalized cheating.

As in Studies 1 and 2, we also explored the efficacy of the NPI in predicting our misconduct measures. Because total NPI scores are more strongly related to grandiosity than entitlement, we expected that if the NPI were able to predict cheating behavior at all, it would be more likely to mirror the hypothesized association between grandiosity and rationalized cheating than between entitlement and deliberative cheating.

\section{Method}

\section{Participants}

Participants were 93 undergraduates from introductory psychology courses at The University of Oklahoma. As compensation, participants received one credit toward their research exposure requirement. At least 3 weeks before participating, participants completed the NPI and the same measures of grandiosity and entitlement used in Studies 1 and 2. Data from 8 participants were excluded because of extreme suspicion $(n=2)$, procedural errors $(n=4)$, or missing data on one or more predictors $(n=2)$, leaving a final sample of 85 participants (62 females, 23 males), of which approximately $78 \%$ were Caucasian.

\section{Procedure}

Our procedure followed closely that described in von Hippel et al. (2005). All participants were told that we were interested in testing the validity of a new computerized test examining cognitive ability. This "Mental Math Task" consisted of two sets of 10 equations each. Each equation consisted of 10 numbers that participants were to add or subtract as directed. The equation would repeat until the participant provided the correct answer. 
Participants were told that because we wanted people to perform as well as possible, the highest scorer would receive a $\$ 30$ prize at the end of the study. Thus, participants believed they were in competition with other participants for this prize. At this time, participants were informed of an unfortunate "bug" with the test program. The experimenter explained that this program was originally designed for another study by the experimenter's advisor. In the original study, the answers were meant to appear automatically, but the experimenter was unable to remove this feature without crashing the program. The experimenter then went on to explain that this glitch should not be a problem because the answer would not appear if a response box were already on the screen. This response box would appear as soon as participants hit the spacebar on their keyboard. Hence, participants could prevent the answer from appearing by simply hitting the spacebar after each equation appeared. The experimenter emphasized the importance of promptly hitting the spacebar when the equation appeared and assured participants that they would have as much time as needed to solve each problem after the response box came up. The experimenter explained that it took about $10 \mathrm{~s}$ for the answer to appear during the first set of 10 equations, so the participant would have plenty of time to hit the spacebar. Following von Hippel et al. (2005), we operationalized deliberative cheating as the number of times participants failed to hit the spacebar within the 10 -s time frame.

After the first set of equations, the experimenter went on to explain, the program would inform the participant that the second set was about to begin. In the second set, however, the answer appeared after only about $1 \mathrm{~s}$. Participants were told that it might be more difficult to hit the spacebar in time in this set, so they should try to hit the spacebar immediately after the questions appeared in the second set. Following von Hippel et al. (2005), we operationalized rationalized cheating as the number of times participants failed to hit the spacebar within the 1-s time frame, controlling for the amount of cheating in the 10-s set (because those who deliberately cheat are likely to do so in both sets, controlling for levels of deliberative cheating in the 10-s set leaves a residual level of cheating in the 1-s set attributable primarily to rationalization processes). After giving participants a final reminder that the response box would only appear if they hit the spacebar, the experimenter left them alone to complete the task.

Following the math task, participants completed several additional measures unrelated to the present study and were then thoroughly probed for suspicion and debriefed. Because participants were not actually competing for $\$ 30$, at the end of the study, the experimenter entered each participant's name in a drawing for the $\$ 30$ prize.

\section{Results and Discussion}

\section{Cheating}

Not surprisingly, cheating occurred significantly more often in the 1 -s set $(M=2.89, S D=3.34)$ than in the 10 -s set $(M=1.88, S D=2.74), t(80)=4.05, p<.001$, presumably reflecting the greater ease of rationalizing misconduct in the former. These results parallel those obtained by von Hippel et al. (2005), although our cheating levels were somewhat lower than those reported in von Hippel et al.'s studies.

\section{Regression Analyses}

The primary analyses involved determining which dimension of narcissism was a significant predictor of cheating in the 10-s and 1-s sets. For these analyses, narcissistic grandiosity and entitlement were each meancentered before the creation of an interaction term (Aiken \& West, 1991). When cheating in the 10-s set was regressed on gender, grandiosity, entitlement, and the Grandiosity $\times$ Entitlement interaction, only entitlement was a significant predictor of deliberative cheating $(\beta=.26, p<.05, d=.46$; all other $p s>.30)$. Entitlement and grandiosity did not interact significantly to predict deliberative cheating.

For rationalized cheating, we first regressed cheating levels in the 1-s set on deliberative cheating in the 10-s set and saved the standardized residuals. Examination of these standardized residuals revealed the presence of two outliers approximately $3 S D$ above the mean, which we removed before conducting our final analysis (removal of these individuals' data did not change the results in the 10-s set). After regressing rationalized cheating on gender, grandiosity, entitlement, and the Grandiosity $x$ Entitlement interaction, only gender $(\beta=-.22, p<.05$, $d=.46)$ and grandiosity $(\beta=.22, p<.05$, one-tailed, $d=.40$ ) predicted rationalized cheating. Neither entitlement nor the Grandiosity $\times$ Entitlement interaction was even close to being significant ( $p s>.20$ ). Thus, entitlement predicted deliberative cheating, whereas grandiosity predicted rationalized cheating, as hypothesized.

In the previous analyses, we determined that grandiosity and entitlement uniquely predicted different types of cheating, but how would the NPI fare as a predictor of misconduct? To answer this question, we regressed both rationalized and deliberative cheating on gender and the NPI. The NPI predicted rationalized cheating to a similar degree as grandiosity $(\beta=.19, p<.05$, onetailed, $d=.39$ ) but was not predictive of deliberative cheating $(\beta=.15, p>.15, d=.30)$. Thus, even though the NPI was able to predict rationalized cheating with similar effectiveness compared to grandiosity, it was unable to predict deliberative cheating very well. 
Consistent with data from Study 2, narcissistic grandiosity and entitlement did not interact to predict the two forms of cheating we examined in this study. Rather, they functioned independently of one another, not simply by accounting for unique variance in cheating scores in an additive fashion but by actually predicting different types of cheating. This pattern of distinct associations complements the results of Study 2, in which we found that grandiosity and entitlement were differentially associated with mental health. Additionally, the inability of the NPI to predict behavior associated with narcissistic entitlement provides further support for the advantages of a reliable, multidimensional approach to narcissism.

\section{GENERAL DISCUSSION}

Given the interest value of narcissism and its place of importance in the history of psychology, it seems odd that social and personality psychologists have relied almost exclusively on a single operational definition of this construct - specifically, scores on the NPI. Indeed, we can think of no other topic in all of psychology in which such an overreliance has occurred to the extent that it has with narcissism. We believe it is time that researchers reconsider how they think about and measure this construct, for both practical and theoretical reasons.

In the present research, we have suggested that a dimensional approach encompassing both an intrapersonal sense of grandiosity and an interpersonal sense of entitlement might effectively capture the essence of narcissism. With this dimensional model in mind, we used two reliable and face-valid measures of grandiosity and entitlement and associated these measures with scores on the NPI and the Big Five, indices of mental health, and two forms of cheating. Only with respect to scores on the NPI did grandiosity and entitlement interact, and the magnitude of that interaction was modest. In all other cases, grandiosity and entitlement behaved independently of one another or even exerted suppressor effects on one another. Indeed, the failure to discover any interactions between grandiosity and entitlement with respect to an outcome other than scores on the NPI calls into question the importance of that single interaction, particularly in light of prior criticisms of this scale. Although parallel associations with mental health have been obtained with a division of the NPI into a two-factor combination of its subscales (e.g., Watson \& Biderman, 1993), the mediocre levels of face validity (especially L/A) and poor reliability (especially E/E and S/A) of the NPI subscales make them less than ideal for capturing narcissistic grandiosity and entitlement, in contrast to the highly face-valid and reliable scales that we used in the present research (see also Campbell et al., 2004).
The present studies, of course, are not without important limitations. First and foremost, the majority of the evidence we report was based on self-report, both on the predictor and criterion sides of the equation. The only exceptions to this design limitation were the measures of deliberative and rationalized cheating in Study 3. In addition, although we captured several classes of outcomes associated with scores on the NPI in prior research (as well as predicting NPI scores themselves), the present studies certainly do not exhaust the range of thoughts, feelings, and behaviors theoretically associated with narcissism. For example, one of the most interesting manifestations of narcissistic egoism can be seen in the aggressive responses to negative feedback exhibited by people with high scores on the NPI. Although Campbell et al. (2004) found that entitlement was predictive of aggressive responses to negative feedback, a measure of grandiosity was not included in Campbell et al.'s study, so we cannot be certain whether this aggression was primarily a function of grandiosity or entitlement, or whether it might be even greater among people high in both grandiosity and entitlement. Additional studies that distinguish between these possible sources of narcissistic rage could provide valuable insights into this particularly dark side of narcissism.

We should also note the possibility that the grandiosity and entitlement scales we used in these studies might not be adequate to capture the intrapersonal and interpersonal facets of the narcissism construct. Social exploitation in particular is not directly measured by the entitlement scale, and exploitation of others appears as a major factor in many discussions of the narcissistic personality (cf. Buss, 1991). Although we acknowledge this limitation, it seems reasonable to predict that social exploitation, lack of empathy, and other interpersonal characteristics described in classic treatments of narcissism might be subsumed under an entitlement factor (Campbell et al., 2004), just as many, if not all, of the self-enhancing characteristics attributed to narcissism might be subsumed under a grandiosity factor. Indeed, we recently obtained evidence consistent with this argument with respect to self-enhancing social comparisons, control beliefs, and empathy (Budzek \& Brown, 2008), but additional research is clearly needed to extend this line of evidence to other variables.

The crucial question now, we suggest, is what to do with the narcissism construct itself. The only data we have across the present three studies that grandiosity and entitlement interact with one another are with respect to the NPI. Otherwise, these dimensions appear to operate independently of one another. Furthermore, grandiosity and entitlement demonstrated distinct associations with respect to mental health (Study 2) and misconduct (Study 3) rather than merely accounting for 
unique but additive variance in these outcomes. These patterns are inconsistent with the expectation that narcissism reflects a special combination of high grandiosity and high entitlement. Rather, the present studies suggest that either high grandiosity or high entitlement might be sufficient to indicate a narcissistic style of thinking, feeling, or behaving.

Keeping these narcissistic dimensions distinct in both theory and practice could clarify some of the contradictory conclusions in the narcissism literature, such as the question of whether narcissism levels are rising in American culture (Trzesniewski et al., 2008, vs. Twenge, Konrath, Foster, Campbell, \& Bushman, 2008) and whether narcissists are truly low in implicit selfesteem (Campbell, Bosson, Goheen, Lakey, \& Kernis, 2007 , vs. Jordan, Spencer, Zanna, Hoshino-Browne, \& Correll, 2003). Perhaps only the sense of entitlement, but not grandiosity, is rising in contemporary American culture (see Trzesniewski et al., 2008), and maybe grandiosity and entitlement are uniquely related to implicit self-esteem (or even to different types of implicit selfesteem, consistent with distinctions suggested by Campbell et al., 2007). Ignoring the differences between grandiosity and entitlement in favor of a simpler, unidimensional narcissism construct could lead to more confusion than clarity regarding such important issues as cultural change and nonconscious elements of the self-concept.

Indeed, given the present data, we are forced to wonder whether we need an overarching narcissism construct at all or whether it might be more appropriate simply to treat grandiosity and entitlement as distinct elements of the self-concept and to measure either or both of these dimensions directly, depending on the research question at hand. Clearly, more research needs to be conducted to address these issues, but we hope the present studies further this debate. Our understanding of what it means to be narcissistic will surely grow through such discourse, however difficult it might be to offer up such a sacred cow on the altar of scientific progress.

\section{REFERENCES}

Aiken, L. S., \& West, S. G. (1991). Multiple regression: Testing and interpreting interactions. Newbury Park, CA: Sage.

American Psychiatric Association. (2000). Diagnostic statistical manual of mental disorders (Revised 4th ed.). Washington, DC: Author.

Brown, R. P., \& Zeigler-Hill, V. (2004). Narcissism and the nonequivalence of self-esteem measures: A matter of dominance? Journal of Research in Personality, 38, 585-592.

Budzek, K., \& Brown, R. P. (2008). Correlations among narcissistic grandiosity, entitlement, empathy, and self-serving illusions. Unpublished raw data: The University of Oklahoma.

Bushman, B. J., \& Baumeister, R. F. (1998). Threatened egotism, narcissism, self-esteem, and direct and displaced aggression: Does self-love or self-hate lead to violence? Journal of Personality and Social Psychology, 75, 219-229.
Buss, D. M. (1991). The psychodiagnosis of everyday conduct: Narcissistic personality disorder and its components. In D. Cicchetti \& W. M. Grove (Eds.), Thinking clearly about psychology: Essays in honor of Paul E. Meehl: Vol. 2. Personality and psychopathology (pp. 333-345). Minneapolis: University of Minnesota Press.

Campbell, W. K., Bonacci, A. M., Shelton, J., Exline, J. J., \& Bushman, B. J. (2004). Psychological entitlement: Interpersonal consequences and validation of a self-report measure. Journal of Personality Assessment, 83, 29-45.

Campbell, W. K., Bosson, J. K., Goheen, T. W., Lakey, C. E., \& Kernis, M. H. (2007). Do narcissists dislike themselves "deep down inside"? Psychological Science, 18, 227-229.

Carroll, L. (1987). A study of narcissism, affiliation, intimacy, and power motives among students in business administration. Psychological Reports, 61, 355-358.

Dickinson, K. A., \& Pincus, A. L. (2003). Interpersonal analysis of grandiose and vulnerable narcissism. Journal of Personality Disorders, 17, 188-207.

Diener, E., Emmons, R. A., Larsen, R. J., \& Griffin, S. (1985). The Satisfaction With Life Scale. Journal of Personality Assessment, 49, 71-75.

Emmons, R. A. (1984). Factor analysis and construct validity of the Narcissistic Personality Inventory. Journal of Personality Assessment, 48, 291-300.

Emmons, R. A. (1987). Narcissism: Theory and measurement. Journal of Personality and Social Psychology, 52, 11-17.

Exline, J. J., Baumeister, R. F., Bushman, B. J., Campbell, W. K., \& Finkel, E. J. (2004). Too proud to let go: Narcissistic entitlement as a barrier to forgiveness. Journal of Personality and Social Psychology, 87, 894-912.

Hendin, H. M., \& Cheek, J. M. (1997). Assessing hypersensitive narcissism: A reexamination of Murray's Narcism Scale. Journal of Research in Personality, 31, 588-599.

Hickman, S. E., Watson, P. J., \& Morris, R. J. (1996). Optimism, pessimism, and the complexity of narcissism. Personality and Individual Differences, 20, 521-525.

John, O. P., Donahue, E. M., \& Kentle, R. L. (1991). The Big Five Inventory-Versions $4 a$ and 54. Berkeley: University of California, Institute of Personality and Social Research.

Jordan, C. H., Spencer, S. J., Zanna, M. P., Hoshino-Browne, E., \& Correll, J. (2003). Secure and defensive high self-esteem. Journal of Personality and Social Psychology, 85, 969-978.

Kernberg, O. F. (1975). Borderline conditions and pathological narcissism. New York: Jason Aronson.

Kubarych, T. S., Deary, I. J., \& Austin, E. J. (2004). The Narcissistic Personality Inventory: Factor structure in a non-clinical sample. Personality and Individual Differences, 36, 857-872.

Leary, T. (1957). Interpersonal diagnosis of personality. New York: Ronald Press.

Morf, C. C., \& Rhodewalt, F. (1993). Narcissism and self-evaluation maintenance: Explorations in object relations. Personality and Social Psychology Bulletin, 82, 668-676.

Morf, C. C., \& Rhodewalt, F. (2001). Unraveling the paradoxes of narcissism: A dynamic self-regulatory processing model. Psychological Inquiry, 12, 177-196.

Paulhus, D. L. (2001). Normal narcissism: Two minimalist accounts. Psychological Inquiry, 12, 228-230.

Radloff, L. S. (1977). The CES-D scale: A self-report depression scale for research in the general population. Applied Psychological Measurement, 1, 385-401.

Raskin, R., \& Hall, C. S. (1979). A Narcissistic Personality Inventory. Psychological Reports, 40, 590.

Raskin, R., Novacek, J., \& Hogan, R. (1991). Narcissistic self-esteem management. Journal of Personality and Social Psychology, 60, 911-918.

Raskin, R., \& Terry, H. (1988). A principal-components analysis of the Narcissistic Personality Inventory and further evidence of its construct validity. Journal of Personality and Social Psychology, 54, 890-902.

Rhodewalt, F., \& Morf, C. C. (1995). Self and interpersonal correlates of the Narcissistic Personality Inventory: A review and new findings. Journal of Research in Personality, 29, 1-23. 
Rhodewalt, F., \& Morf, C. C. (1998). On self-aggrandizement and anger: A temporal analysis of narcissism and affective reactions to success and failure. Journal of Personality and Social Psychology, 74, 672-685.

Rosenberg, M. (1965). Society and the adolescent self-image. Princeton, NJ: Princeton University Press.

Rosenthal, S. A., \& Hooley, J. M. (2008). Revisiting the Narcissistic Personality Inventory: Does it measure narcissism, self-esteem, or both? Manuscript submitted for publication.

Rosenthal, S. A., Hooley, J. M., \& Steshenko, Y. (2007). Distinguishing grandiosity from self-esteem: Development of the Narcissistic Grandiosity Scale. Manuscript in preparation.

Ruiz, J. M., Smith, T. W., \& Rhodewalt, F. (2001). Distinguishing narcissism and hostility: Similarities and differences in interpersonal circumplex and five-factor correlates. Journal of Personality Assessment, 76, 537-555.

Scheier, M. F., Carver, C. S., \& Bridges, M. W. (1994). Distinguishing optimism from neuroticism (and trait anxiety, self-mastery, and self-esteem): A reevaluation of the Life Orientation Test. Journal of Personality and Social Psychology, 67, 1063-1078.

Sedikides, C., Campbell, W. K., Reeder, G. D., Elliot, A. J., \& Gregg, A. P. (2002). Do others bring out the worst in narcissists? The "others exist for me" illusion. In Y. Kashima, M. Foddy, \& M. Platow (Eds.), Self and identity: Personal, social, and symbolic (pp. 103-124). Mahwah, NJ: Lawrence Erlbaum.

Sedikides, C., Rudich, E. A., Gregg, A. P., Kumashiro, M., \& Rusbult, C. (2004). Are normal narcissists psychologically healthy? Selfesteem matters. Journal of Personality and Social Psychology, 87, 400-416.

Sobel, M. E. (1982). Asymptotic intervals for indirect effects in structural equations models. In S. Leinhart (Ed.), Sociological methodology 1982 (pp. 290-312). San Francisco: Jossey-Bass.

Soyer, R. B., Rovenpor, J. L., Kopelman, R. E., Mullins, L. S., \& Watson, P. J. (2001). Further assessment of the construct validity of four measures of narcissism: Replication and extension. Journal of Psychology, 135, 245-258.
Taylor, S. E., \& Brown, J. D. (1988). Illusion and well-being: A social psychological perspective on mental health. Psychological Bulletin, 103, 193-210.

Trzesniewski, K. H., Donnellan, M. B., \& Robins, R. W. (2008). Do today's young people really think they are so extraordinary? An examination of secular trends in narcissism and selfenhancement. Psychological Science, 19, 181-188.

Twenge, J. M., Konrath, S., Foster, J. D., Campbell, W. K., \& Bushman, B. J. (2008). Egos inflating over time: A cross-temporal meta-analysis of the Narcissistic Personality Inventory. Journal of Personality, 76, 875-902.

von Hippel, W., Lakin, J. L., \& Shakarchi, R. J. (2005). Individual differences in motivated social cognition: The case of self-serving information processing. Personality and Social Psychology Bulletin, 31, 1347-1357.

Watson, P. J., \& Biderman, M. D. (1993). Narcissistic Personality Inventory factors, splitting, and self-consciousness. Journal of Personality Assessment, 61, 41-57.

Watson, P. J., \& Morris, R. J. (1990). Irrational beliefs and the problem of narcissism. Personality and Individual Differences, 11, 1137-1140.

Westen, D. (1990). The relations among narcissism, egocentrism, selfconcept, and self-esteem: Experimental, clinical, and theoretical considerations. Psychoanalysis \& Contemporary Thought, 13, 183-239.

Wiggins, J. S. (1979). A psychological taxonomy of trait-descriptive terms: The interpersonal domain. Journal of Personality and Social Psychology, 37, 395-412.

Wiggins, J. S., \& Pincus, A. L. (1994). Personality structure and the structure of personality disorders. In P. T. Costa \& T. A. Widiger (Eds.), Personality disorders and the five-factor model of personality (pp. 73-93). Washington, DC: American Psychological Association.

Wink, P. (1991). Two faces of narcissism. Journal of Personality and Social Psychology, 61, 590-597.

Received July 14, 2008

Revision accepted February 18, 2009 